\title{
Morphometry and morphology of glenoid fossa of scapula
}

\author{
Sinha Rajiv R ${ }^{1}$, Kumar Binod ${ }^{2, *}$, Kulkarni Jyoti. P $^{3}$ \\ ${ }^{1,2}$ Associate Professor, ${ }^{3}$ Additional Professor, Dept. of Anatomy, Indira Gandhi Institute of Medical Sciences, Patna, Bihar, India
}

*Corresponding Author:

Email: jyopidhut@gmail.com

Received: $15^{\text {th }}$ February, 2018

Accepted: $8^{\text {th }}$ May, 2018

\begin{abstract}
Introduction: In the complex anatomy of shoulder joint one of the articular surfaces is the truncated glenoid fossa. The objective of the study is to observe the shape of the glenoid fossa and perform morphometric study in detail in the dry scapulae.

Materials and Methods: The study was conducted on 38 dry human scapulae of unknown age and sex. The shape was observed $\&$ measurements were recorded with the help of digital vernier calliper.

Result: Pear shape glenoid fossa with shallow notch was seen in $55.26 \%$ of right scapula and $26.31 \%$ of left scapula, while pear shape glenoid fossa with a deep notch was seen in $5.26 \%$ of right scapula and $13.1 \%$ of left scapula. There was no significant difference between the mean transverse diameters of right and left glenoid fossa. The mean vertical diameter was larger than other diameters.

Conclusion: The glenoid fossa is largely pear shaped because the superior transverse diameter is less than the inferior transverse diameter. The notch on the anterior margin of glenoid fossa due to the tendon of subscapularis may be shallow or significantly deep. The depth of the notch does not correlate with the handedness of the individual. The range of the overall dimensions of the glenoid fossa with deep anterior notch are larger. Morphological and morphometric observations of the study are important in prosthesis design of glenoid fossa and demography of other shoulder diseases.
\end{abstract}

Keywords: Glenoid fossa, Glenoid rim, Notch, Anterior margin, Diameter.

\section{Introduction}

The scapula or the shoulder blade is a triangular flat bone lying on the dorsolateral aspect of thoracic cage extending from $2^{\text {nd }}$ to $7^{\text {th }}$ rib. It has three angles namely the superior angle, Inferior angle and lateral angle. The lateral angle is truncated. It is the thickest part of the bone and bears the broad head of the scapula. The glenoid fossa is the primary feature of the head. It is also called as glenoid cavity. It is a shallow concave oval fossa directed anterolaterally and slightly superiorly. ${ }^{1}$ It serves as a socket for the head of the humerus. However the head of the humerus is considerably larger than the glenoid fossa. The upper one third of the glenoid fossa ossifies from the subcoracoid centre. Subcoracoid centre is a secondary centre of ossification which appears at or soon after puberty and fuses at 14 years in females and 17 years in males. One secondary centre for ossification appears in the lower glenoid rim. This lower glenoid rim is thick peripherally and converts the child's flat cavity into a gentle concave pear shaped adult fossa ${ }^{2}$ with a notch on its anterior margin. Variant morphology and morphometry of the glenoid fossa is influenced by environmental and genetic factors. The shoulder is the third most common large joint, which requires surgical reconstruction after knee and hip. Due to complex anatomy of the joint it is important to understand the dimensions of the screw and implants to be used. Glenoid fossa requires reconstruction using implants in shoulder arthroplasty. There is paucity of data regarding the morphological assessment and morphometry of the glenoid fossa in the region of Bihar. The aim \& objective of the present study is to observe the shape of the glenoid fossa and perform morphometric study in detail in the dry human scapulae. It is essential for better understanding of shoulder arthroplasty in the management of glenohumeral arthritic conditions, shoulder dislocations, rotator cuff disorders and management of other demographic diseases pertaining to shoulder. ${ }^{3}$

\section{Materials and Methods}

The present study was conducted on 38 dry human scapulae in Department of Anatomy and Department of Forensic medicine in Indira Gandhi Institute of Medical sciences. The age and sex of the scapulae were unknown. The measurements were recorded on the glenoid fossa of the right and left scapulae with the help of digital vernier calliper in millimetre (Fig. 1). The various parameters were used for statistical analysis. Following parameters of the glenoid fossa were studied

1. The shape of the glenoid fossa was observed.

2. The vertical diameter of the glenoid fossa was measured from outer margin of glenoid fossa below supraglenoid tubercle to outer margin of glenoid fossa above infraglenoid tubercle.

3. Superior Transverse diameter was the minimum diameter measured at a distance of $8.7 \mathrm{~mm}$ from the apex of supraglenoid tubercle.

4. Middle transverse diameter was midway between superior and inferior transverse diameter.

5. Inferior transverse diameter was the maximum diameter measured at a distance of $11.6 \mathrm{~mm}$ from the apex of infraglenoid tubercle. 
6. Oblique diameter was measured from posterior point of superior transverse diameter to the anterior point of inferior transverse diameter.

The Range, mean and standard deviation correlating with the shape and the notch were calculated separately for the right and left glenoid fossa with the help of a statistician.

\section{Results}

Total 38 dry human scapula of unknown age and sex were studied, of which 23 were right scapula and 15 were left scapula.

Pear shape glenoid fossa with shallow notch (Fig 3 ) on the upper part of anterior margin was seen in $55.26 \%$ of right scapula and $26.31 \%$ of left scapula, while pear shape glenoid fossa with a deep notch on the upper part of anterior margin (Fig 2) was seen in 5.26\% of right scapula and $13.1 \%$ of left scapula.

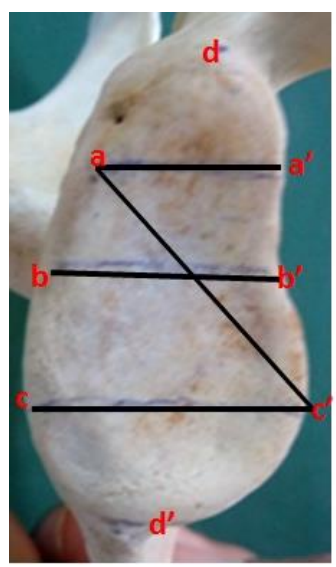

Fig. 1: aa' - Superior transverse diameter, bb' Middle transverse diameter, $\mathbf{c}$ c'-Inferior transverse diameter, dd'- vertical diameter, ac' oblique diameter

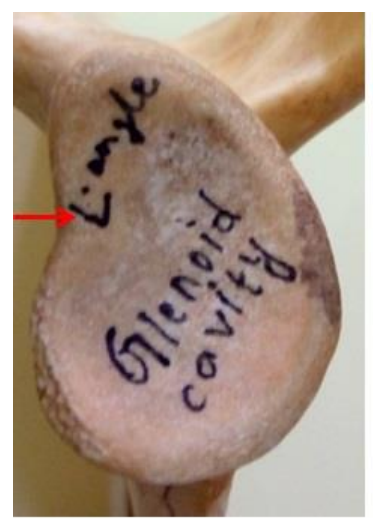

Fig. 2: Pear shaped glenoid fossa of left scapula with Red arrow pointing towards the deep notch on the anterior margin of the glenoid fossa
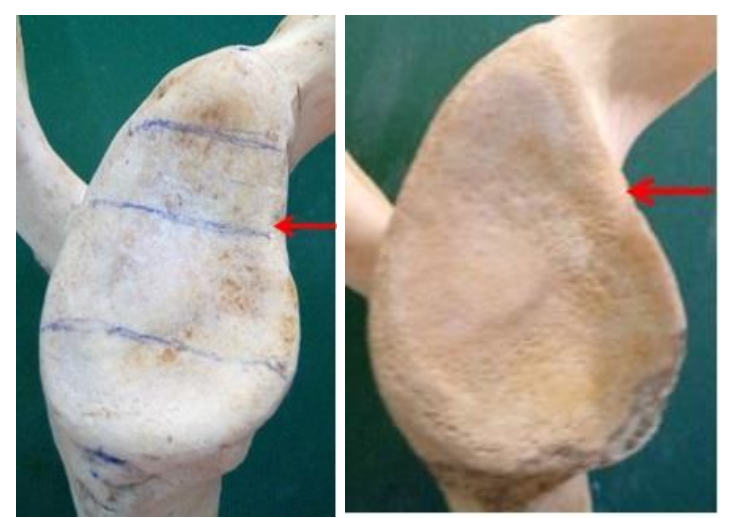

Fig. 3 \& 4: Pear shaped glenoid fossa of Right scapula with Red arrow pointing towards the shallow notch on the anterior margin of the glenoid fossa

\section{Discussion}

In the present study the shape of the glenoid fossa was largely pear shape in all the specimens of scapula. Pear shape is described as the shape which is broad towards the base and narrows towards the apex.

Observations of present study concurs with studies done by other authors as seen in table $2 \mathrm{a}$. However we differ in opinion about oval shape as mentioned by above mentioned authors. Oval shape is elliptical wherein the superior transverse diameter and inferior transverse diameter should be same. In pear shape as mentioned earlier the base is broad and narrows towards the apex. So glenoid fossa is largely pear shaped because the superior transverse diameter is always less than the inferior transverse diameter as mentioned in the observations Table 1.

The anterior margin of the glenoid fossa towards its upper part showed presence of notch. This notching is due to the tendon of subscapularis. The notch was shallow in $55.26 \%$ of right scapula and $26.31 \%$ of left scapula, while the notch was significantly deep in $5.26 \%$ of right scapula and $13.1 \%$ of left scapula. The depth of the notch is probably influenced by the degree of friction between the tendon and the bone with the intervening subscapular bursa in between them. Incidence of distinct or deep notch is very less in the present study, which differs from the findings of Coskun N. ${ }^{4}$ (28\% distinct notch), Mamatha et al ${ }^{5}$ (34\% deep notch) where the incidence is relatively high. When the glenoid notch is deep the glenoid labrum is not intimately attached to the rim of the glenoid at the site of notch, which can be a predisposing factor in anterior dislocation of shoulder joint. ${ }^{6}$

In the present study the range of the overall dimensions as observed in Table 1, the diameters of the glenoid fossa with deep anterior notch are larger as compared to that of the shallow notch glenoid fossa.

In the present study the mean of various diameters of glenoid fossa of right and left scapula was calculated and compared with the studies of other Indian and 
International authors (Table 2b). The various diameters of the glenoid fossa in the present study as observed from table $2 b$ when compared with the findings of various authors, show variations. The mean superior transverse diameter in the present study concurs with that of Hina B Rajput, Kintu K Vyas, Bhavesh D Shroff, ${ }^{7}$ but it is less when compared with studies of Coskun $\mathrm{N}^{4}$ and Churchill R S, Brems JJ and Kotschi $\mathrm{H}^{8}{ }^{8}$ The mean of middle transverse diameter is more than that of Hina B Rajput, Kintu K Vyas, Bhavesh D Shroff $^{7}$ and Gosavi S.N, Jadhav S.D and Garud R.S, ${ }^{9}$ but less than that of Ajay Kumar Mahto and Saif Omar $^{10}$ and Coskun N. ${ }^{4}$ The mean of inferior transverse diameter is less when compared with that of Piyawinjiwong S. ${ }^{11}$ The findings of mean oblique diameter and vertical diameter concurs with that of the other studies. The differences in the mean diameters amongst various authors is probably due to the slight variations in the reference points used for measuring the various diameters.

The present study agrees with Mamatha et $\mathrm{al}^{5}$ and Gosavi S.N, Jadhav S.D. ${ }^{9}$ that handedness does not influence the morphology and morphometry of the glenoid fossa. The functional study done by Marisa E. Macias and Steven E. Churchill revealed that side, sex and lifestyle does not correlate with the morphology. ${ }^{12}$ Measurement of the vertical length and the transverse length of the glenoid cavity are very important parameters in deciding the length of screw implants in reverse total shoulder arthroplasty. Based on these measurements in women and smaller individuals i.e males and females smaller base plates of prosthesis is required which is determined by preoperative $\mathrm{CT} .^{13}$

Table 1: Morphometry of glenoid fossa

\begin{tabular}{|c|c|c|c|c|c|c|c|c|c|c|c|c|}
\hline \multirow[t]{2}{*}{ Diameter } & \multicolumn{3}{|c|}{$\begin{array}{l}\text { Right Scapula, Pear } \\
\text { shape glenoid cavity } \\
\text { with shallow notch }\end{array}$} & \multicolumn{3}{|c|}{$\begin{array}{l}\text { Right Scapula, Pear } \\
\text { shape glenoid cavity } \\
\text { with deep notch }\end{array}$} & \multicolumn{3}{|c|}{$\begin{array}{c}\text { Left Scapula Pear } \\
\text { shape glenoid cavity } \\
\text { with shallow notch }\end{array}$} & \multicolumn{3}{|c|}{$\begin{array}{l}\text { Left Scapula Pear } \\
\text { shape glenoid cavity } \\
\text { with deep notch }\end{array}$} \\
\hline & Range & Mean & SD +/- & Range & Mean & $\begin{array}{l}\text { SD } \\
+/-\end{array}$ & Range & Mean & SD +/- & Range & Mean & SD +/- \\
\hline $\begin{array}{l}\text { Superior transverse } \\
\text { diameter }\end{array}$ & 6.29 & 14.26 & 1.35 & 2.38 & 15.49 & 1.68 & 3.11 & 13.73 & 1.09 & 3.15 & 13.31 & 1.20 \\
\hline $\begin{array}{l}\text { Middle transverse } \\
\text { diameter }\end{array}$ & 12.58 & 20.3 & 2.49 & 1.78 & 20.02 & 1.25 & 4.26 & 19.99 & 1.62 & 3.05 & 20.50 & 1.20 \\
\hline $\begin{array}{l}\text { Inferior transverse } \\
\text { diameter }\end{array}$ & 8.43 & 22.7 & 2.56 & 3.51 & 23.44 & 2.48 & 5.66 & 21.52 & 2.14 & 3.43 & 22.9 & 1.4 \\
\hline Oblique diameter & 14.55 & 24.74 & 3.31 & 2.12 & 22.69 & 1.49 & 10.22 & 22.22 & 3.40 & 7.51 & 23.2 & 2.3 \\
\hline Vertical diameter & 12.09 & 34.2 & 3.60 & 4.58 & 32.61 & 3.23 & 8.69 & 33.03 & 3.31 & 7.51 & 33.4 & 3.04 \\
\hline
\end{tabular}

Table 2a: Comparison of morphology in present study with other studies

\begin{tabular}{|c|c|c|c|c|c|c|}
\hline \multirow[t]{2}{*}{ Authors } & \multicolumn{3}{|c|}{ Right Scapula Glenoid fossa } & \multicolumn{3}{|c|}{ Left Scapula Glenoid fossa } \\
\hline & Pear Shape & Oval & $\begin{array}{c}\text { Inverted coma } \\
\text { shape }\end{array}$ & Pear Shape & Oval & $\begin{array}{c}\text { Inverted } \\
\text { coma shape }\end{array}$ \\
\hline Rajput et al ${ }^{3}$ & $49 \%$ & $16 \%$ & $35 \%$ & $46 \%$ & $17 \%$ & $39 \%$ \\
\hline Mamatha et $\mathrm{al}^{4}$ & $46 \%$ & $20 \%$ & $34 \%$ & $43 \%$ & $24 \%$ & $33 \%$ \\
\hline Hamed $\mathrm{G}$ et al $^{14}$ & $44.74 \%$ & $23.68 \%$ & $31.58 \%$ & $46.67 \%$ & $23.33 \%$ & $30 \%$ \\
\hline Akhtar $\mathrm{MJ}^{15}$ & $51.59 \%$ & $13.49 \%$ & $34.92 \%$ & $49.02 \%$ & $13.73 \%$ & $37.25 \%$ \\
\hline $\begin{array}{l}\text { Pranoti Sinha }{ }^{16} \text { et } \\
\text { al }\end{array}$ & $23 \%$ & $8 \%$ & $9 \%$ & $42 \%$ & $13 \%$ & $6 \%$ \\
\hline Gosavi S.N $\mathrm{N}^{8}$ et al & $54.83 \%$ & $32.25 \%$ & $12.9 \%$ & $45 \%$ & $43.75 \%$ & $11.2 \%$ \\
\hline Present Study & $\begin{array}{c}\text { With shallow notch } \\
-56.26 \% \\
\text { With deep notch - } \\
5.26 \%\end{array}$ & nil & nil & $\begin{array}{c}\text { With shallow } \\
\text { notch }- \\
26.31 \% \\
\text { With deep } \\
\text { notch }-13.1 \%\end{array}$ & nil & nil \\
\hline
\end{tabular}

Table 2b: Comparison of mean of various diameters in present study and other studies

\begin{tabular}{|l|c|c|c|c|c|}
\hline & $\begin{array}{c}\text { Superior transverse } \\
\text { diameter }(\mathbf{m m})\end{array}$ & $\begin{array}{c}\text { Middle transverse } \\
\text { diameter }(\mathbf{m m})\end{array}$ & $\begin{array}{c}\text { Inferior transverse } \\
\text { diameter }(\mathbf{m m})\end{array}$ & $\begin{array}{c}\text { Vertical } \\
\text { diameter }(\mathbf{m m})\end{array}$ & $\begin{array}{c}\text { Oblique } \\
\text { diameter }(\mathbf{m m})\end{array}$ \\
\hline Present study & Rt with shallow notch- & Rt with shallow & Rt with shallow & Rt with shallow & Rt with shallow \\
& $14.3 \pm 1.4$ & notch-20.3 2.5 & notch-22.7 \pm 2.5 & notch-34.2 \pm 3.6 & notch-24.7 \pm 3.3 \\
& Rt with deep notch-15.5 \pm 1.7 & Rt with deep notch- & Rt with deep notch- & Rt with deep & Rt with deep \\
& Lt with shallow notch & $20 \pm 1.25$ & $23.4 \pm 2.5$ & notch-32.6 \pm 3.2 & notch-22.7 \pm 1.5 \\
& $13.7 \pm 1.09$ & Lt with shallow & Lt with shallow notch & Lt with shallow & Lt with shallow \\
& Lt with deep notch- & notch $19.9 \pm 1.6$ & $21.5 \pm 2.1$ & notch33.03 \pm 3.3 & notch $-22.2 \pm 3.4$ \\
& $13.3 \pm 1.20$ & Lt with deep notch- & Lt with deep notch- & Lt with deep & Lt with deep \\
\hline
\end{tabular}




\begin{tabular}{|c|c|c|c|c|c|}
\hline & & $20.5 \pm 1.2$ & $23 \pm 1.3$ & notch-33.3 \pm 3.04 & notch-23.2 \pm 2.8 \\
\hline Coskun N. & - & $24.6 \pm 2.5$ & & 36.3 & - \\
\hline $\begin{array}{l}\text { Mamatha T, Pai S } \\
\text { R, Murlimanju } \\
\text { BV, Kalthur SG, } \\
\text { Pai MM, Kumar } \\
\text { B }^{5} \\
\end{array}$ & $\begin{array}{l}\text { Rt } 23.35 \pm 2.04 \\
\text { Lt } 23.05 \pm 2.3\end{array}$ & - & $\begin{array}{c}\text { Rt } 23.02 \pm 2.3 \\
\text { Lt } 23.31 \pm 2.3\end{array}$ & $\begin{array}{c}\text { Rt-33.67 } \pm 2.82 \\
\text { Lt }-33.92 \pm 2.87\end{array}$ & - \\
\hline \begin{tabular}{|l|} 
Hina B. Rajput, \\
Kintu K Vyas, \\
Bhavesh D \\
Shroff $^{7}$ \\
\end{tabular} & $\begin{array}{c}\text { Rt } 15.10 \pm 2.5 \\
\text { Lt } 13.83 \pm 2.4\end{array}$ & $\begin{array}{c}\text { Rt } 16.2 \pm 3.2 \\
\text { Lt } 15.24 \pm 2.04\end{array}$ & $\begin{array}{c}\text { Rt } 23.3 \pm 3 \\
\text { Lt } 22.92 \pm 2.8\end{array}$ & $\begin{array}{c}\text { Rt } 34.76 \pm 3 \\
\text { Lt } 34.43 \pm 3.2\end{array}$ & $\begin{array}{c}\text { Rt } 23.08 \pm 3.2 \\
\text { Lt } 24.64 \pm 2.1\end{array}$ \\
\hline Churchill et al ${ }^{8}$ & $27.9 \pm 1.6$ & - & - & $\begin{array}{l}\text { Male37.5 } \pm 2.82 \\
\text { Female32.6 } \pm 1.8\end{array}$ & - \\
\hline $\begin{array}{l}\text { Dr. Gosavi S.N., } \\
\text { Dr. Jadhav S.D., } \\
\text { Dr. Garud R.S }{ }^{9} \\
\end{array}$ & $\begin{array}{l}\text { Rt } 17.72 \pm 1.8 \\
\text { Lt } 16.82 \pm 2.2\end{array}$ & 14.58 & $\begin{array}{l}\text { Rt } 24.17 \pm 2.6 \\
\text { Lt } 23.9 \pm 2.7\end{array}$ & $35.03 \pm 5.25$ & - \\
\hline $\begin{array}{l}\text { Ajay Kumar } \\
\text { Mahto, Saif } \\
\text { Omar }^{10}\end{array}$ & - & $\begin{array}{c}\text { Rt } 24.2 \pm 0.13 \\
\text { Lt } 22.5 \pm 0.14\end{array}$ & & $\begin{array}{l}\text { Rt } 36.2 \pm 0.17 \\
\text { Lt } 33.2 \pm 0.18\end{array}$ & - \\
\hline $\begin{array}{l}\text { Piyawinijiwong } \\
\mathrm{S}^{11} \\
\end{array}$ & - & & $\begin{array}{l}\text { Rt } 29.1 \pm 2.6 \\
\text { Lt } 25.6 \pm 2.5\end{array}$ & 33.6 & - \\
\hline $\begin{array}{l}\text { Md. Jawed } \\
\text { Akhtar, Bipin } \\
\text { Kumar, Nafees } \\
\text { Fatima, Vinod } \\
\text { Kumar }^{15} \\
\end{array}$ & $\begin{array}{c}\text { Rt } 23.6 \pm 2.5 \\
\text { Lt } 23.59 \pm 2.5\end{array}$ & - & $\begin{array}{c}\text { Rt } 16.30 \pm 2.16 \\
\text { Lt } 16 \pm 2.34\end{array}$ & $\begin{array}{l}\text { Rt } 36.03 \pm 3.2 \\
\text { Lt } 35.5 \pm 3.1\end{array}$ & - \\
\hline $\begin{array}{l}\text { Pranoti Sinha, } \\
\text { Karma Lakhi } \\
\text { Bhutia, Binod } \\
\text { Kumar Tamang, } \\
\text { Rohit Kumar } \\
\text { Sarda } 16 \\
\end{array}$ & $\begin{array}{c}\text { Rt } 18.08 \pm 2.6 \\
\text { Lt } 18.01 \pm 2.5\end{array}$ & - & $\begin{array}{c}\text { Rt } 23.2 \pm 2.8 \\
\text { Lt } 23.3 \pm 3.12\end{array}$ & $\begin{array}{l}\text { Rt } 33.61 \\
\text { Lt } 34.45\end{array}$ & - \\
\hline
\end{tabular}

\section{Conclusion}

The glenoid fossa is largely pear shaped because the superior transverse diameter is less than the inferior transverse diameter. The notch on the anterior margin of glenoid fossa due to the tendon of subscapularis may be shallow or significantly deep. The depth of the notch does not correlate with the handedness of the individual. The range of the overall dimensions of the glenoid fossa with deep anterior notch are larger. Morphological and morphometric observations of the study are important in prosthesis design of glenoid fossa and demography of other shoulder diseases. Morphology and morphometry of the glenoid fossa of scapula shows variations among different population groups. These observations are vital in implant manufacturing and surgical interventions at shoulder joint. The various diameters and morphology discussed in the present study will help to decide the size of glenoid component in shoulder arthroplasty.

Limitation of the Study: For further conclusions the study should be carried out on a larger sample size on dry bones and imaging. The samples included in the study were of unknown sex and age, hence the parameters could not be correlated with age and sex.

\section{References}

1. Keith L. Moore, Arthur F. Dalley. Ch 6 Upper Limb, Bones of Upper \& Lower Limbs/Scapula. Clinically Oriented Anatomy, $5^{\text {th }}$ edition, Lippincott Williams and Wilkins, Wolter Kluwer Company, 2006, p. 730.

2. Williams P Bannister LH, Berry MM, Collins P, Dyson M, Dussek JE, et al. Ch 6 Skeletal system, Roger W Soames. Gray's Anatomy. The Anatomical Basis of Medicine and Surgery. $38^{\text {th }}$ ed. Edinburgh, London: Churchill Livingstone; 1995. Pg.615-619.

3. Wael Amin Nasr El-Din, Mona Hassan Mohammed Ali. A morphometric study of the patterns and variations of the acromion and glenoid cavity of the scapula in Egyptian population. J Clin Diagn Res. 2015 Aug;9(8):AC08-11.

4. Coskun N. Anatomical basics and variations of the scapulae in Turkish adults. Saudi Med J. 2006;27:1320-5.

5. Mamatha T, Pai S R, Murlimanju BV, Kalthur SG, Pai MM, Kumar B. Morphometry of Glenoid Cavity. Online J Health Allied Scs. 2011;10(3):7.

6. Prescher A, Klumpen T. The Glenoid notch and its relation to the shape of the glenoid cavity of the scapula. J Anat. 1997;190:457-60. 
7. Hina B. Rajput, Kintu K Vyas, Bhavesh D Shroff. A study of morphological patterns of glenoid cavity of scapula. National Journal of Medical Research. Oct Dec 2012; Vol 2(4):504-507.

8. Churchill RS, Brems JJ, Kotschi H, Glenoid size, inclination and version: An anatomic study. J shoulder Elbow Surgery. 2001;10:327-332.

9. Gosavi S.N., Jadhav S.D., Garud R.S. Morphometric study of scapular glenoid cavity in Indian population. IOSR-Journal of Dental and Medical Sciences. Sept 2014, Vol 13(9), 67-69.

10. Ajay Kumar Mahto, Saif Omar. Dimensions of Glenoid fossa of scapula: Implications in the biomechanics of an implant design. International Journal of Scientific Study. July 2015; Vol. 3(4):146-148.

11. Piyawinijiwong S. The Scapulae: Osseous dimensions and gender dimorphism in Thais. Siriraj Hosp Gaz. 2004;56:356-65.

12. Marisa E.Macias, Steven E. Churchill. Functional morphology of the Neandertal scapula glenoid fossa. The anatomical record. 2015;298:168-179.

13. Sandra Mathews, Marco Burkhard, Nabil Serrano, Karl Link, Martin Hausler, Nakita Frater, Ingebork Franke, Helena Bischofberger, Florian M. Buck, Dominic Gascho, Michael Thali, Steffen Serowy, Magdalena Muller-Gerbi, Gareth Harper, Ford Quershi, Thomas Boni, Hans Rudolf Bloch, Oliver Ullrich, Frank-Jakobus
Ruhli, Elisabeth Eppler. Glenoid Morphology in light of anatomical and reverse total shoulder arthroplasty: a dissection and 3D CT-based study in male and female body donors. BMC Musculoskeletal disorders. 2017;18:9. doi: 10.1186/s12891-016-1373-4.

14. Gamal Hamed, El-Sayed Hassanein. Morphometry of Glenoid fossa in adult Egyptian scapulae. International Journal of Anatomy and Research. May 2015;Vol.3(2):1138-42.

15. Md. Jawed Akhtar, Bipin Kumar, Nafees Fatima, Vinod Kumar. Morphometric analysis of glenoid cavity of dry scapula and its role in shoulder prosthesis. International Journal of Research in Medical Sciences. July 2016;4(7):2770-2776.

16. Pranoti Sinha, Karma Lakhi Bhutia, Binod Kumar Tamang, Rohit Kumar Sarda. Morphometric study of glenoid cavity of dry human scapula. International Journal of Medical Research Professionals. 2016;2(3):86-90.

How to cite this article: Sinha RR, Kumar B, Kulkarni JP. Morphometry and morphology of glenoid fossa of scapula. Ind $\mathbf{J}$ Clin Anat Physiol. 2018;5(3):303-307. 